\title{
PENGARUH BRIEFING KERJA DAN PERAN SUPERVISOR TERHADAP KINERJA KARYAWAN PADA PT.GMF AEROASIA Tbk.
}

\author{
Dadang \\ Fakultas Ekonomi dan Bisnis, Universitas Muhammadiyah Tangerang \\ azqi_ihsan@yahoo.co.id \\ Feri Heriyanto \\ Fakultas Ekonomi dan Bisnis, Universitas Muhammadiyah Tangerang
}

\begin{abstract}
Abstrak
Tujuan dari penelitian ini untuk mengetahui pengaruh briefing kerja dan peran Supervisor terhadap kinerja karyawan pada PT.GMF Aeroasia Tbk. Penelitian ini menggunakan pendekatan kuantitatif. Populasi dalam penelitian ini sejumlah 150 karyawan PT.GMF Aeroasia Tbk. pada unit Third Party Line Maintenance Bandara Internasional Soekarno Hatta. Teknik pengambilan sampel yang digunakan adalah purposive sampling dan diperoleh sampel sebanyak 60 responden. Teknik analisis data yang digunakan adalah regresi linear berganda.Hasil penelitian menunjukkan bahwa secara parsial briefing kerja berpengaruh positif dan signifikan terhadap kinerja karyawan. Untuk variabel peran Supervisor secara parsial berpengaruh positif dan signifikan terhadap kinerja karyawan. Secara simultan briefing kerja dan peran Supervisor berpengaruh positif dan signifikan terhadap kinerja karyawan Kemampuan variabel briefing kerja dan peran Supervisor dalam menjelaskan kinerja karyawan sebesar $89,1 \%$ sebagaimana ditunjukkan dengan besarnya $R$ square sebesar 0,891
\end{abstract}

Kata kunci : Kinerja Karyawan, Briefing Kerja dan Peran Supervisor.

\begin{abstract}
The purpose of this study was to determine the effect of work briefing and supervisor role on the employee performance of PT. GMF Aeroasia Tbk. in Third Party Line Maintenance Unit at Soekarno Hatta International Airport. This study uses a quantitative approach. The population in this study were 150 employee of PT. GMF Aeroasia Tbk. in Third Party line Maintenance unit at Soekarno Hatta International Airport. The sampling technique used was purposive sampling and obtained a sample of 60 respondents. The data analysis technique used is multiple linear regression. The results showed that partially the work briefing had a positive and significant effect on employee performance. For supervisor role variables partially have a positive and significant effect on employee performance. Simultaneously work briefing and supervisor role have a positive and significant effect on purchasing decisions. The ability of work briefing variables and supervisor role in explaining purchasing decisions is $89.1 \%$ as indicated by the $R$ square value of 0.891 while the remaining $10.9 \%$ is influenced by other factors not included in the research model.
\end{abstract}

Keywords: work briefing, supervisor role, employee performance. 


\section{A. PENDahuluan}

\section{Latar Belakang Masalah}

Dalam dunia penerbangan, PT. GMF Aeroasia adalah salah satu member dari Garuda Indonesia Group, dan salah satu perusahaan perawatan pesawat terbang yang terbesar di Asia. Visi PT. GMF Aeroasia adalah menjadi 10 besar perusahaan perawatan pesawat terbang di dunia. Banyaknya perusahaan penerbangan yang bangkrut dan juga bermunculan beberapa perusahaan serupa merupakan bukti bahwa persaingan dalam dunia penerbangan sangat ketat. Hal ini menjadi sebuah tantangan tersendiri bagi perusahaan yang memiliki karyawan sekitar 4500 karyawan itu untuk bisa maju dan berkembang. Dengan bertambahnya beban kerja, PT. GMF Aeroasia harus berbenah. Selain menambah karyawan, produktifitas karyawan juga harus ditingkatkan. Agar produktivitas karyawan meningkat, di perlukan beberapa program diantaranya mewajibkan briefing kerja setiap hari minimal selama 10 menit sebelum memulai pekerjaan. Selain menerapkan briefing kerja, ada faktor lain yang tak kalah penting dalam meningkatkan produktifitas karyawan yaitu peran Supervisor. Supervisor adalah salah satu jabatan yang penting dalam sebuah perusahaan. Secara struktur jabatan, supervisor berada di bawah Manajer dan berada langsung di atas karyawan produksi. Oleh karena itu peran supervisor yang paling utama adalah mendeskripsikan apa yang disampaikan perusahaan kepada karyawan agar tujuan perusahaan tercapai. Selain itu Supervisor juga bertanggung jawab terhadap seluruh hasil pekerjaan.

Adapun Identifikasi Masalah dalam penelitian ini adalah adanya penambahan beban kerja pada perusahaan yang menuntut peningkatan produktivitas karyawan. Lalu, Koordinasi dan kerjasama antar karyawan belum terjalin dengan baik. Berikutnya, SOP (Standar Operasional Prosedur) dalam bekerja belum sepenuhnya dipahami oleh seluruh karyawan. Selanjutnya, Masih terdapat keluhan dari konsumen karena kesalahan karyawan terutama dalam masalah administrasi. Serta Masih kurangnya pengetahuan karyawan tentang peraturan keselamatan terutama karyawan baru. Dan Kurangnya komunikasi antara atasan dan bawahan. Dalam penulisan penelitian ini penulis membatasi masalah tentang pengaruh briefing kerja dan peran Supervisor terhadap kinerja karyawan pada PT. GMF Aeroasia tbk. unit Third Party Line Maintenance.

Adapun motivasi penelitian ini adalah untuk mengetahui Apakah briefing kerja berpengaruh terhadap kinerja karyawan PT. GMF Aeroasia tbk. Lalu, Apakah peran Supervisor berpengaruh terhadap kinerja karyawan PT. GMF Aeroasia tbk. Dan Apakah briefing kerja dan peran Supervisor berpengaruh secara 
simultan terhadap kinerja karyawan PT. GMF Aeroasia tbk.

\section{B. TINJAUAN PUSTAKA DAN PERUMUSAN HIPOTESIS}

\section{Manajemen}

Definisi manajemen menurut George R. Terry (2013) yang dialih Bahasa oleh G.A. Ticoalu adalah suatu proses yang khas yang terdiri atas tindakantindakan perencanaan, pengorganisasian, pergerakan dan pengendalian yang dilakukan untuk menentukan serta mencapai sasaran yang telah ditentukan melalui pemanfaatan sumber daya manusia atau sumber daya lainnya.

Berdasarkan pada penjelasan diatas, dapat penulis tarik kesimpulan bahwa pengertian manajemen adalah suatu kegiatan usaha yang telah memiliki perencanaan dan pengendalian dalam suatu organisasi guna mencapai tujuan yang diharapkan melalui pemanfaatan sumber daya manusia dan sumber daya lainnya secara efektif dan efisien.

\section{Manajemen Sumber Daya Manusia (MSDM).}

Manajemen Sumber Daya Manusia (MSDM) adalah suatu perencanaan, pengorganisasian, pengarahan, dan pengawasan atas pengadaan, pengembangan, kompensasi, pengintegrasian, pemeliharaan dan pemutusan hubungan kerja dengan maksud untuk mencapai tujuan organisasi perusahaan secara terpadu (Husein Umar, 1998) dalam buku Danang Sunyoto (2015)

Dari beberapa devinisi diatas penulis dapat menarik kesimpulan bahwa Manajemen Sumber Daya Manusia merupakan suatu proses menangani berbagai masalah pada ruang lingkup organisasi atau perusahaan, mulai dari seleksi karyawan hingga Pemutusan Hubungan Kerja (PHK) melalui proses planning, organizing, actuating, dan controlling, untuk dapat menunjang aktivitas organisasi atau perusahaan demi mencapai tujuan yang di tetapkan.

\section{Kinerja Karyawan.}

Berdasarkan pendapat para ahli, definisi kinerja adalah sebagai hasil kerja yang dicapai oleh individu yang di sesuaikan dengan peran atau tugas individu tersebut dalam suatu organisasi yang di hubungkan dengan suatu ukuran nilai atau standar tertentu dari organisasi atau perusahaan dimana individu itu bekerja.

\section{Briefing Kerja.}

Menurut Liong (2013)
Mengatakan bahwa "Briefing
adalah suatu pengarahan atau
proses membahas yang ada di
depan ataupun sesuatu yang
belum terjadi. Briefing harus
diberikan setiap saat kepada para
karyawan dan bawahan untuk
mensosialisasikan aturan-aturan
yang telah di buat". Djajendara
(2015) menyatakan bahwa "
Breifing adalah komunikasi tatap
muka yang paling efektif dan
cepat untuk menjalankan tugas


sehari-hari dan untuk menyatukan persepsi dan arah kerja tim". Menurut Bernadeta (2014) bahwa "Briefing adalah komunikasi yang paling efektif untuk saling menguatkan peran kerja, meguatkan komitmen bersama, dan meningkatkan etos untuk mencapai kinerja terbaik.

\section{Peran Supervisor}

Menurut Arif Rahman

Kurniawan (2016) Supervisor adalah manajer yang bertanggung jawab kepada manajer yang lebih tinggi dan tugas utamanya memimpin pekerjaan pada taraf operasional. Menurut Sarwoto (1993) Supervisor adalah seorang di suatu organisasi yang bertanggung jawab atas tugas terhadap kelompoknya. Sedangkan menurut Moekijat (1990) Supervisor adalah anggota perusahaan yang bertanggung jawab atas pekerjaan anak buahnya kepada manajemen yang lebih tinggi.

\section{Hipotesis Penelitian}

Dari uraian masalah yang ada dapat dimunculkan syarat hipotesis penelitian ini sebagai berikut:

$\mathrm{H}_{1}$ :Briefing kerja berpengaruh terhadap kinerja karyawan

$\mathrm{H}_{2}$ :Peran supervisor berpengaruh terhadap kinerja karyawan.

\section{METODOLOGI PENELITIAN}

\section{Pendekatan Penelitian}

Penulis melakukan suatu metode penelitian dengan cara penelitian kuantitatif karena analisis data yang peneliti lakukan bersifat kauntitatif/ statistic. Untuk alamat perusahaan PT. GMF Aeroasia tbk. Jl. GMF Aeroasia, Pajang, Benda, Kota Tangerang, Banten 15126, atau perkantoran Bandara Internasional Seokarno Hatta Tamgerang Banten. Tempat penelitian ini dilakukan di Terminal 2F Bandara Internasional Soekarno Hatta, Tangerang. Adapun waktu penelitian dilaksanakan pada bulan Juni 2019 sampai dengan Agustus 2019

\section{HASIL PENELITIAN DAN PEMBAHASAN}

1. Gambaran Umum Responden

Berdasarkan hasil tanggapan responden, maka dibawah ini akan di jelaskan terlebih dahulu mengenai identitas responden berdasarkan jenis kelamin, usia, pekerjaan dan pendidikan terakhir.

\section{Tabel 1}

Data Demografi Responden

\begin{tabular}{|l|c|c|}
\hline \multicolumn{1}{|c|}{ Jenis Kelamin } & Jumlah & Persentase \\
\hline Laki-Laki & 54 & $90 \%$ \\
\hline Perempuan & 6 & $10 \%$ \\
\hline \multicolumn{1}{|c|}{ Usia } & 0 & $0 \%$ \\
\hline <18 Tahun & 36 & $60 \%$ \\
\hline 19-29 Tahun & 15 & $25 \%$ \\
\hline 30-40 Tahun & 9 & $15 \%$ \\
\hline$>40$ Tahun & \multicolumn{2}{|c|}{} \\
\hline Pendidikan Terakhir & 0 & $0 \%$ \\
\hline SD & 0 & $0 \%$ \\
\hline SMP & 50 & $84 \%$ \\
\hline SMA & 6 & $10 \%$ \\
\hline Diploma & 4 & $6 \%$ \\
\hline S1 & 0 & $0 \%$ \\
\hline S2/S3 & & \\
\hline
\end{tabular}


2. Analisis Deskriptif Variabel

Berdasarkan tabel diatas dapat dijelaskan bahwa nilai mean terkecil adalah 3,73 pada pernyataan kuesioner 7 yaitu "Karyawan dapat menyampaikan keluh kesahnya pada Briefing kerja", sedangkan nilai mean terbesar adalah 4,33 pada kuesioner pernyataan 1 yaitu "Komunikasi karyawan menjadi lebih efektif". Hal ini berarti bahwa hampir semua responden memberikan nilai positif terhadap adanya Briefing kerja.

\section{Hasil Uji Validitas}

Berdasarkan pengujian pada tabel uji validitas diatas, diketahui bahwa nilai $r$ hitung dari semua indikator variabel lebih besar dari $r$ tabel nya. Oleh karena itu dapat disimpulkan bahwa semua indikator dalam penelitian ini adalah valid.

\section{Hasil Uji Reliabilitas}

Tabel 2

\section{Hasil Uji Reliabilitas}

\begin{tabular}{|c|c|c|}
\hline Variabel & $\begin{array}{c}\text { Cronbach's } \\
\text { Alpha }\end{array}$ & Status \\
\hline $\begin{array}{c}\text { Briefing Kerja } \\
\left(\mathrm{X}_{1}\right)\end{array}$ & 0,859 & Reliabel \\
\hline $\begin{array}{c}\text { Peran Supervisor } \\
\left(\mathrm{X}_{2}\right)\end{array}$ & 0,791 & Reliabel \\
\hline $\begin{array}{c}\text { Kinerja } \\
\text { Karyawan (Y) }\end{array}$ & 0,831 & Reliabel \\
\hline
\end{tabular}

$$
\text { Berdasarkan pengujian }
$$

pada tabel uji reliabilitas diketahui bahwa semua variabel mempunyai Cronbach Alpha lebih besar dari 0,60 maka dapat disimpulkan bahwa

keseluruhan variabel dalam penelitian ini adalah realiabel.

\section{Hasil Uji Multikolonieritas}

Tabel 3 Hasil Uji Multikolonieritas

\begin{tabular}{|c|c|c|}
\hline Variabel & Tolerance & VIF \\
\hline $\begin{array}{c}\text { Briefing } \\
\text { Kerja }\end{array}$ & 0.327 & 3.005 \\
\hline $\begin{array}{c}\text { Peran } \\
\text { Supervisor }\end{array}$ & 0.327 & 3.005 \\
\hline
\end{tabular}

Dari hasil uji yang dilakukan, maka dapat diambil kesimpulan bahwa model regresi dalam penelitian ini tidak ada masalah multikolonieritas, berarti antar variabel independen tidak saling berkorelasi sempurna.

\section{Hasil UjiHeteroskedastisitas}

Hasil heteroskedastisitas dapat dilihat pada gambar 1 berikut ini :

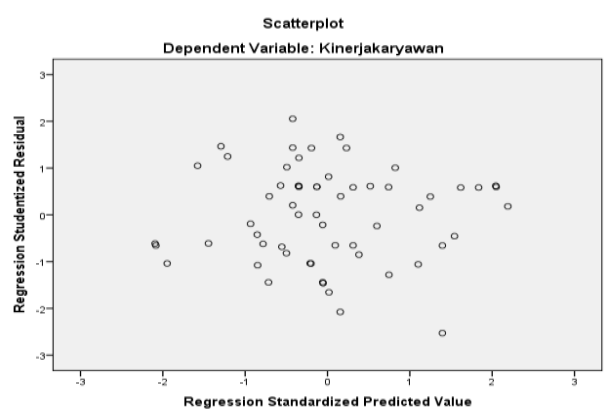

Gambar 1 Hasil UjiHeteroskedastisitas 
7. Hasil Uji Normalitas

Hasil uji normalitas dapat dilihat pada gambar 2 berikut ini :

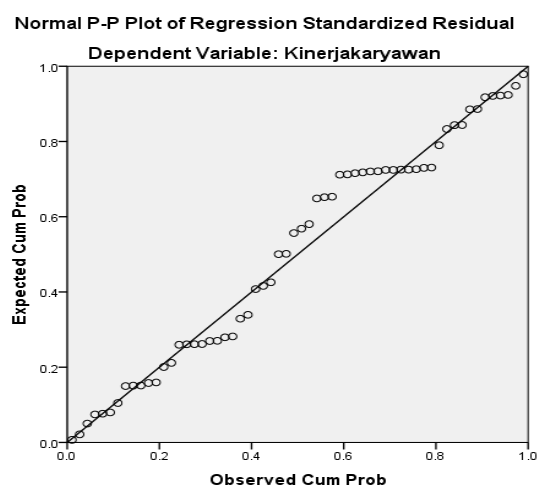

Gambar 2 Hasil Uji Normalitas

\section{Hasil Uji Regresi Linier Berganda.}

Hasil uji regresi linier berganda dengan menggunakan aplikasi computer IBM SPSS Statistic dapat dilihat pada tabel 4 berikut ini :

Tabel 4

Hasil Uji Regresi Linier Berganda

Coefficients $^{a}$

\begin{tabular}{|c|c|c|c|c|c|}
\hline \multirow[b]{2}{*}{ Model } & \multicolumn{2}{|c|}{ Unstandardized Coefficients } & \multirow{2}{*}{$\begin{array}{c}\begin{array}{c}\text { Standardized } \\
\text { Coefficients }\end{array} \\
\text { Beta } \\
\end{array}$} & \multirow[b]{2}{*}{$\mathrm{t}$} & \multirow[b]{2}{*}{ Sig. } \\
\hline & B & Std. Error & & & \\
\hline (Constant) & -.494 & 1.881 & & -.262 & .794 \\
\hline Briefing Kerja & .677 & .077 & .670 & 8.756 & .000 \\
\hline Peran supervisor & .327 & .080 & .313 & 4.087 & .000 \\
\hline & & & $\begin{array}{l}\text { F }_{\text {hitung : }} .232 .255 \\
\text { R}_{\text {Square: }} .891\end{array}$ & $\begin{array}{l}\text { F sig: } \\
F_{\text {tabel: }}:\end{array}$ & \\
\hline
\end{tabular}

a. Dependent Variable: Kinerja karyawan

\section{Hasil Uji Hipotesis}

a. Pengaruh Briefing kerja terhadap Kinerja Karyawan

Berdasarkan

hasil penelitian dapat diketahui bahwa variabel Briefing kerja berpengaruh terhadap Kinerja Karyawan secara parsial terlihat dari uji $\mathrm{t}$ dimana nilai $t_{\text {hitung }}(8,756)>$ $t_{\text {table }}(2,003)$. Maka Briefing kerja berpengaruh positif dan signifikan terhadap Kinerja Karyawan pada PT. GMF Aeroasia Tbk unit Third Party Line Maintenance Di Bandara Soekarno-Hatta. 


\section{b. Pengaruh \\ Supervisor \\ Peran \\ Kinerja Karyawan}

Berdasarkan hasil

penelitian dapat diketahui bahwa variabel Peran

Supervisor berpengaruh terhadap Kinerja Karyawan secara parsial terlihat dari uji t dimana $t$ hitung (4.087) $>\mathrm{t}$ table (2,003). Maka Peran Supervisor berpengaruh positif dan signifikan terhadap Kinerja Karyawan pada PT. GMF Aeroasia Tbk. unit Third Party Line Maintenance di Bandara Internasional Soekarno Hatta

\section{E. KESIMPULAN DAN SARAN \\ 1. Kesimpulan}

a. Terbukti bahwa Briefing kerja berpengaruh positif dan signifikan terhadap Kinerja karyawan pada PT. GMF Aeroasia Tbk. unit Third Party Line Maintenance di Bandara Internasional Soekarno-Hatta

b. Terbukti bahwa Peran Supervisor berpengaruh positif dan signifikan terhadap kinerja karyawan pada PT. GMF Aeroasia Tbk. unit Third Party Line Maintenance di Bandara Internasional Soekarno-Hatta

c. Terbukti bahwa Briefing kerja dan Peran Supervisor berpengaruh positif dan signifikan terhadap Kinerja karyawan pada PT. GMF Aeroasia Tbk. unit Third Party Line Maintenance di Bandara Internasional Soekarno Hatta
2. Saran

a. Bagi PT. GMF Aeroasia Tbk. hendaknya briefing kerja dijadikan budaya untuk di lakukan setiap hari pada setiap unit dan juga di buat SOP mengenai briefing kerja sehingga bisa menjadi budaya perusahaan dan dapat mendukung program perusahaan

b. Bagi peneliti diharapkan dapat terus memperdalam dan mengaplikasikan teori tentang briefing kerja dan peran Supervisor dan dapat mengaplikasikannya di dunia pekerjaan..

c. Bagi karyawan diharapkan briefing kerja ini menjadi budaya kerja, dan membiasakan mengikuti briefing sebelum bekerja sehingga hal-hal yang akan di sampaikan oleh atasan dapat di terima dengan baik

\section{DAFTAR PUSTAKA}

AA. Anwar Prabu Mangkunegara, 2013, Manajemen Sumber Daya Manusia

Afnisa, Shella. 2017. Pengaruh Briefing

Kerja Dan Pelatihan Kerja Terhadap Motivasi Karyawan Pada Perusahaan Lanud Driving Range Medan.

Bango, Haryanto. 2018. Pengaruh Harga dan Kualitas Pelayanan Terhadap Keputusan Pembelian Pengguna Jasa Penerbangan Maskapai Sriwijaya Air Di 
Bandara Internasional Soekarno Hatta.

Djajendra, 2014. "Briefing Adalah

Komunikasi Tatap Muka Yang Menyatukan Pimpinan Dengan Stafnya." https://DjajendraMotivator.Com/?P=8981, diakses pada 29 April 2019 pukul 20.30 WIB.

Ghozali, Imam. 2013. Aplikasi Analisis Multivariate Dengan Program SPSS. Semarang: Badan Penerbit UNDIP.

Liong, Freddy. 2013. Morning Briefing At Work. Jakarta: PT. Gramedia Pustaka Utama. Perusahaan, Bandung: PT. Remaja Rosdakarya.

PT. GMF-Aeroasia tbk. 2019. "About GMF." http://www.gmfaeroasia.co.id/about-gmf/. Diakses pada 20 April 2019 pada pukul 20.30 WIB.

Quality \& Procedure. "Struktur organisasi PT. GMF Aeroasia." https://gmfaeroasia365.sharepoint. com/Pages/landingpage.aspx/.

Diakses pada 20 Agustus 2019 pada pukul 20.00 WIB.

Rakhman Kurmiawan, Arief. 2016. Buku Sakti Manajer dan Supervisor. Yogyakarta: Quadrant.

Roziq, Fadlu. 2012. Pengaruh Peran Supervisor Dalam Program Pelatihan Pada Prestasi Kerja Karyawan Dengan otivasi Belajar Sebagai Variabel Pemediasi.
Skripsi. Surakarta: Univarsitas Sebelas Maret Surakarta.

Sedarmayanti. 2010. Sumber Daya Manusia dan Produktivitas Kerja, Bandung: CV Mandar Maju.

Sugiyono, 2016. Metode Penelitian Manajemen, Bandung: Alfabeta

Sugiyono, 2017. Metode Penelitian

Kualitatif, Kuantitatif, dan R\&D, Bandung: Alfabeta.

Sunyoto, Danang. 2012. Manajemen Sumber Daya Manusia. Yogyakarta: Caps.

Terry, George R. 2013. Dasar-Dasar Manajemen, (Terjemah: G.A Ticoalu), CV. Bandung: Alfabeta. Utami, Ika Putri. 2016. Analisi Pengaruh Peran Supervisor Dan Pelatihan Trrhadap Kinerja Tenaga penjualan PT. Nasmoco Gomberl Semarang. Jurnal Studi Kasus Pada Sales Operation PT. Nasmoco Gombel Semarang. 9(3).

Virmansyah, 2018. "Mengenal Tugas Supervisor \& Tanggung Jawabnya Di Perusahaan.” https://www.ruangpegawai.com/ra gam/mengenal-tugas-supervisortanggung-jawabnya-diperusahaan-1198, diakses pada 29 April 2019 pukul 19.30 WIB. 